\title{
Research on Innovative and Entrepreneurial Education System in Colleges and Universities Based on the Cooperation Mechanism of Government and Enterprise
}

\author{
Xingwei Qu, Wenqian Luo, Hongying Cheng \\ Shaanxi Fashion Engineering University, Xixian new area. Shaanxi, 712000
}

Keywords: cooperation mechanism; government and enterprise; Double Creation education

\begin{abstract}
China is currently undergoing economic transformation and structural adjustment. The call for "mass entrepreneurship and innovation" aims to encourage the creativity of the whole people, develop smart wealth, expand the employment connotation, and condense the core competitiveness of talents. "Forewarned is forearmed, without prejudging the waste". "Mass entrepreneurship and innovation" education must go ahead, and colleges and universities are of course the "double creation" main front. How to adapt to the current "double creation" new environment and new background, and then optimize the talent training and education structure of colleges and universities, explore new ways for the development of higher education in China, and make the cultivation of talents in colleges and universities become a new guide to promote economic and social development.
\end{abstract}

\section{Introduction}

The entrepreneurial education carried out by local colleges and universities, from the initial simple imitation to the practice exploration under the guidance of the government, to the emergence of different development models today, has shown the process of internal reform of higher education. However, under the new normal of China's economic and social development, the development of local colleges and universities faces many challenges, such as: the cultivation of talents and the integration of industry, academia and research are difficult; the links of teachers, courses and practice are weak, and today's education enters "Internet + education". "Mode, traditional educational teaching concepts, methods and methods need to be changed. Local colleges and universities, especially private undergraduate colleges, must identify their own ecological orientation, take the initiative to change, integrate innovation and entrepreneurship into the school-running philosophy, integrate into the whole process of education and teaching, combine their own school environment, school characteristics, professional expertise, outstanding features, and fully mobilize The faculty and students' enthusiasm for innovation and entrepreneurship actively explore and realize the effective integration of local and self-owned resources, and fulfill the task of training the application-oriented talents entrusted by the government and society in the era of "mass innovation and entrepreneurship", reflecting the private colleges and universities. self value [1].

The inevitable requirement of comprehensive reform of higher education carries out comprehensive reforms in the field of education. Improving the level of social and economic development of education services is an urgent need to promote economic development and comprehensively deepen reform. Innovation and entrepreneurship education is an innovation and awakening of traditional education and traditional employment education in terms of content and methods. The "Implementation Opinions of the General Office of the State Council on Deepening the Reform of Innovation and Entrepreneurship Education in Colleges and Universities" clearly pointed out that innovation and entrepreneurship education is a breakthrough in deepening the comprehensive reform of higher education. Local colleges and universities are an important part of higher education reform. It is also necessary to upgrade the innovation and entrepreneurship education to the height of promoting local college reform. 
The private colleges and universities take the education group's "political school and enterprise" integration cooperation platform as the organizational basis, and highly integrate the resources of the government, schools, industries, and enterprises to jointly create a multi-functional enterprise such as entrepreneurship education, practice, service, and incubation. In one integrated entrepreneurial service system, the establishment of a sustainable development entrepreneurial ecosystem with the participation of "political schools and enterprises" and exploring an effective way to cultivate new innovative and entrepreneurial talents is an era requirement of "all-people entrepreneurship and innovation". It has important practical significance and promotion value.

To realize "innovation, public support, crowdfunding", it is necessary to construct an innovative and entrepreneurial education teaching system that suits the professional characteristics of the school. It is necessary to build a platform for innovation and entrepreneurship and create a good environment for innovation and entrepreneurship. Based on the professional characteristics, Shaanxi Garment Engineering College has established an Innovation and Entrepreneurship Institute headed by the head of the College of Education, and the Academic Affairs Office is the responsible unit. The Joint Youth League Committee, the Student Office, the Employment Office, the Experimental Teaching Base, and the Innovation and Entrepreneurship Complex of the University. In accordance with the idea of "creative, innovation, entrepreneurship, one industry", the whole chain service, collaborative innovation and education mode, and the national innovation and entrepreneurship base - Xixian New District, West Anhui New City, the construction of Shaanxi Garment Engineering College, creating space such as the full chain innovation and entrepreneurship incubation carrier. At present, the school offers 6 courses of innovative and entrepreneurial courses, and the number of students participating in and completing the course is more than 2,200. Maker Space has settled in more than 10 enterprises and teams, forming 5 registered enterprises, recruiting more than 120 entrepreneurial partners and participating students. One outstanding graduate was recommended by Xixian New District to be nominated for Shaanxi Provincial College Student Entrepreneur Star [2].

\section{Construction of an Innovation and Entrepreneurship Education System}

Establish a number of educational level linkage mechanisms to achieve the liaison channels for general high school education, secondary vocational education, specialist higher vocational education and general higher education, and actively explore the establishment of an education-employment "revolving door" mechanism for the profession of first-line technical skills. Development provides effective support. This kind of cohesive system helps to break the concept that the university decides everything, so that students have more choices and there is room for choice between theoretical study and technical study. China's vocational and technical education started late, but in recent years, it has developed rapidly. China's labor population has a large base and the scale of vocational education has increased dramatically. However, the ecological chain of vocational education is not yet perfect. Vocational education students have no significant competitive advantage compared with other college students, which leads to the general inferiority complex of this group. In fact, this is only a different division of work, does not mean the level of the level. According to the "National Medium- and Long-Term Education Reform and Development Plan (2010-2020)" issued by the Ministry of Education, China has to achieve " 22.5 million students in secondary vocational education by 2015 and 13.9 million higher vocational education". aims. However, according to the current assessment, there are still nearly one-fourth of the student quotas in vocational education in China. The professional and technical talents need no further development and further study. The problem that was originally difficult to answer now has the conditions for answering--With the rapid development of China's economy and rapid adjustment of the structure, China Manufacturing is creating a key node for China to cross. Quality technical talents have become scarce resources, which give a good answer: Professional and technical personnel also need further study. In this way, China's human resources can break through the bottleneck of low-end processing, and achieve the optimization of skills and the development of professional diversification. Only by opening the level can China's human resources form a complete ladder structure [3]. 
First of all, innovate the concept of development, tailor-made, and identify the development orientation of the institutions. In the reform of colleges and universities, some colleges and universities have transformed into applied universities to adapt to the new situation of the local regional economy, the new development of the industry, and the new changes in the format. This is the dialectical relationship between cognition and reality. It is necessary to raise awareness on the basis of reality and to act on reality from the perspective of understanding. In this way, we can identify the growth point of economic and social development, the shortage of talent gap, and the entry point of reform and development. This has formed a group of distinctive service industry and advanced technology application technology universities and colleges. Secondly, build a school-enterprise, school-site cooperation mechanism, and achieve wide coverage, broad integration, and long-term cooperation. The Guiding Opinions place special emphasis on professional clusters. How to feature the specialty, we should see if it is closely related to the industrial cluster, whether it can achieve the interaction and promotion of professional and cluster. Innovative transformation of colleges and universities can broaden their thinking. For example, they can jointly form an education group with industries and enterprises, or they can jointly build a secondary college with industry clusters. As long as it is conducive to the development of higher vocational students, which is conducive to the expansion of social employment and is conducive to China's economic and social development, it is a model worthy of trial. The full participation of off-campus resources in school management, professional construction and curriculum setting will help to cultivate compound technical talents in a targeted manner. This is an important means to solve the gap in human resources in China, and it is also a prerequisite for good practice in the transformation of colleges and universities. The understanding of the development will not be able to talk about the transformation and how to transform. Finally, build a talent training structure as needed, optimize the training process, and set up a major around the industry chain and innovation chain to help form a specialized cluster. Traditional theoretical majors have their advantages, but they cannot meet the growing economic development and spiritual and material needs. It is especially important to transform traditional professions and establish new composite majors. You can adopt the "Course Supermarket" model, and cultivate the skills of compound skills according to the concept of priority and interest. Similarly, there must be an appropriate evaluation mechanism for the optimized training mode. These two systems are like the two ends of the rope, connecting students on one side and connecting teachers on the other. Establish a system of professional setting evaluation in the industry and employer experts to change the tendency of professionally setting blind pursuit of quantity, and concentrate on the professionalism of enterprises with urgent needs, outstanding advantages and distinctive characteristics.

\section{Innovation and Entrepreneurship Support and Promotion Mechanism}

Innovation is the soul of a nation's progress and an inexhaustible motive force for a country's prosperity. In recent years, China has attached great importance to the "double innovation" work, and the central and local governments have issued a number of policies to support the encouragement of society to innovate and start businesses. However, during the implementation, the communication between the departments was not smooth enough, and there was a cross-repetition phenomenon. In addition, it was difficult to follow up the supporting measures, resulting in a discount on the policy effect. There is still a lot of room for improvement in our policy implementation. As a manager and server of the society, the government needs to further optimize the innovation environment and enhance the enthusiasm for innovation in the whole society. As an important area of reform, colleges and universities should start from their own to create a reform and upgraded version of innovative and entrepreneurial education. According to the "Guiding Opinions", in promoting and improving the mechanism of innovation and entrepreneurship, we should improve the mechanism mainly from the following aspects:

Incorporate advanced technology transfer, innovation and transformation into the comprehensive evaluation standards of colleges and universities, and regard teaching quality and innovation and entrepreneurship education as important contents of teacher performance evaluation, and establish 
personnel training, scientific research quality standards, internal control system and evaluation system to adapt to applied universities [4].

Strengthen the degree of integration of industry and professional, the level of experimental practice training and professional education, the proportion and quality of dual-teacher team. Build a complete integration of the breadth and depth of school-enterprise cooperation, so that the professional settings of colleges and universities adapt to the new development of new industries, new formats and new technologies. Colleges and universities, especially application-oriented colleges, should optimize the structure of expenditures, and lean toward experimental training internships and the construction of "double-skilled dual-energy" teachers, and support the whole process of graduate entrepreneurship. Actively support innovation, take schools as the main body, explore models such as entrepreneurs and social capital cooperation, and attract social investment for incubators and entrepreneurial parks. We will strengthen confidence in reform and form a joint force for reform. Extensively organize relevant departments and experts and scholars to discuss research. Create an innovative and entrepreneurial atmosphere in the school, publicize the value of innovation and entrepreneurship, organize the news media to timely publicize and report the pilot experience, use examples to tell the experience, and use experience to combine reality [5].

\section{Conclusion}

Reform and opening up is not only the opening of the economy, but also the development and opening up of people. Education reform is of great importance and urgency. It must have a general view of adapting and leading the new normal of economic development and service innovation. If our education system cannot establish a set of educational models that conform to the laws governing the development of our people, it will inevitably affect the effect of reform and opening up. Therefore, education reform is an important task in socialist construction. We must promote the transformation and development of universities in the spirit of reform and innovation.

\section{Acknowledgements}

Fund: Shaanxi province higher education teaching reform research project "private colleges and universities innovation and entrepreneurship education teaching system construction and research" one of the research achievements (project number: 17BY123)

\section{References}

[1] Wang Yimei. Practice and Research of Innovation and Entrepreneurship Education in the New Period [J].Western Quality Education, 2017(13):74- 76

[2] Wang Yimei. Research on the Reform and Innovation of Practical Teaching of Information Majors in Private Universities in the Transition Period [J]. Writing (Late), 2016(12): 95- 96

[3] Wang Yimei. Research on Talent Training Model from the Perspective of Innovation and Entrepreneurship [J]. Education Review (first half of the month), 2017.6(9): 69- 70

[4] Wang Bo. Research on the development of the concept of "double innovation" in colleges and universities and its path [J]. Heilongjiang Higher Education Research, 2016(3): 53 - 56.

[5] Mathing. Talent training mode, labor market and employment of college students [J]. Higher Education Research, 2013(3): 34 - 39. 